\title{
Customer Dissatisfaction Index and its Improvement Costs
}

\author{
Aleksandrs Lvovs (M.Sc.Ing., Riga Technical University, Faculty of Power and Electrical Engineering), Anna \\ Mutule (Dr.Sc.Ing., Riga Technical University, Faculty of Power and Electrical Engineering)
}

\begin{abstract}
The paper gives description of customer dissatisfaction index (CDI) that can be used as reliability level characterizing factor. The factor is directly joined with customer satisfaction of power supply and can be used for control of reliability level of power supply for residential customers. CDI relations with other reliability indices are shown. Paper also gives a brief overview of legislation of Latvia in power industry that is the base for CDI introduction. Calculations of CDI improvement costs are performed in the paper too.
\end{abstract}

Keywords - CAIDI, Customer Dissatisfaction Index, distributed generation, non-supply costs, Reliability of power supply, SAIFI

\section{INTRODUCTION}

Nowadays management of electric power systems is changing a lot because of restructuring processes that take place in many countries. The processes of restructurization of power supply companies - monopolies, result in creation of new companies (usually subsidiary companies are created). After restructurization, power generation companies work as separate companies and participate in electricity market. Power transmission and distribution companies usually are monopoles. In order to prevent usage of monopoly state of such companies for getting high profit, some supervision institutions must be organized. As power transmission and distribution companies try to diminish their expenses, parameters of quality of electrical power and reliability of power supply should be strictly defined in legislation in order to not allow diminishing expenses by rendering bad quality services. Normative documentation that regulates activities of power supply companies should be improved or developed anew.

Nowadays to quantify the reliability of a distribution network different indices are used. Most commonly are used SAIFI, SAIDI, CAIDI and EENS. Definitions of most commonly used indices could be found in IEEE Standard 1366 [1]. Disadvantage of the most existing indices are that they quantify system averages, but they don't express feelings of customers that go through power supply interruptions and because of that we can't express how a customer experiences the reliability of supply. Usage of Customer Dissatisfaction Index (CDI) can help us to understand how a customer experiences the reliability of power supply.

In this paper there is given a brief insight of Latvian national politics for power industry, then CDI, developed by authors of [2], is described. After the introduction of the index, CDI value reduction costs are calculated. At the last part of the paper some possible ways of application of CDI and the results of calculation of $\mathrm{CDI}$ value reduction costs are discussed.

\section{II.LATVIAN NATIONAL POLITICS FOR POWER INDUSTRY}

To form and to realize the national politics for power industry some basic principles of development should be drown up. In Latvia there are developed so called "Basic viewpoints of development of power industry". The last "Basic viewpoints of development of power industry" were developed for the time period from 2007 to 2016 [3] (Viewpoints). The goal of the document is to develop strategy for reliable and effective (from the point of view of usage of energy) power supply system.

According to the Viewpoints it is planned to increase reliability level of power supply by increasing the part of energy that is produced at local power plants in overall power consumption (by creating special conditions for increasing local power generation) and by diversification of the ways of power supply. Production of energy at local power plants can include cogeneration power plants and distributed generation.

\section{A. Reliability of Power Supply in Distribution Network}

Power supply interruptions are mainly caused by faults in middle or low voltage networks [4]. According to [3] present situation in Latvia's middle and low voltage network results frequent power supply interruptions or limitation of quantity of electrical energy. Such situation can be explained by bad technical conditions of equipment (especially in rural territories, where power consumption is low and reconstruction of network doesn't pay back). Unfortunately, up to now in legislation of Latvia there are no strictly defined criteria that would make power supply companies to care for diminishing time and number of interruptions. The only number is mentioned in legislation is that power supply interruption should be eliminated in 24 hours, except situations if the reason of interruption is some kind of natural disaster or if there is energy crisis in region.

According to [5] power supply interruptions can be classified in such way:

- Planned interruptions (in this case consumers ought to be informed about interruptions);

- Unexpected interruptions (such interruptions are caused by permanent faults or transient faults, that in their turn are caused by faults or failures of equipment or other external factors).

Unexpected interruptions can be classified in such way: 
- Short-term interruptions (interruption time is under 3 minutes);

- Long-term interruptions (interruption time is over 3 minutes). Further in text there will be used two types of long interruptions - just long interruption (time of interruption is longer than 3 minutes, but doesn't exceed 8 hours) and very long interruption with duration longer than 8 hours.

Legislation of Latvia doesn't have any paragraph dedicated to compensation to consumers for power supply interruptions, even in case when such interruptions are the reason of economical losses. The only way to get some compensation is to include some additional points to contract between consumer and power supply company, that would make the company to pay losses of consumer.

Taking into account all that have been written previously, we can conclude that there is no legislation in Latvia that would give us some definite criteria of power supply reliability. According to Latvia's legislation it is possible to interrupt power supply for 23 hours and 59 minutes, then provide power supply for 1 minute and again interrupt power supply. Such situation is possible because in legislation there is mentioned only time of power interruption, but power supply interruption frequency is not limited. Power supply companies also have no responsibility for damages made by power supply interruptions to consumers' equipment.

Such situation should be changed and it could be done in two parallel ways - creating some dynamic models of existing power system network to provide the optimal way of developing of existing power supply system and evaluating outage costs, or also called costs of non-supply, or using some other ways of evaluating effect of power supply interruptions for individual consumers or consumer groups.

\section{CUSTOMER Dissatisfaction InDEX}

\section{A. Satisfaction and dissatisfaction of customers}

According to [2], customers complaint only in case if they had more than 3 power supply interruptions per year, or in case if power supply interruption lasted more than 8 hours. Customers that had not more than 3 interruptions, less than 8 hours each, didn't complain or complained very rarely. Based on this observation we can bring new definition of "acceptable supply" for a customer. This definition means that power supply reliability is acceptable if there are three or less interruptions per year, each shorter than 8 hours, as shown in Fig. 1. This also could be called "FT" criterion - where F means frequency of interruptions, but $\mathrm{T}$ means duration of interruptions. The number of interruptions experienced by a customer during a year is shown on vertical axes; but the longest interruption experienced by customer during the year is shown on horizontal axes.

\section{B. Definition of CDI}

CDI can be defined as the probability that reliability of power supply for a given customer is insufficient. It is assumed in this paper that insufficient power supply reliability appear in case if customer has more than three interruptions of power supply or if duration of at least one of the interruptions is longer than 8 hours (see Fig. 1). Short interruptions that last less than 3 minutes or less, are not taken into account. CDI value is valid for particular load-point (i.e. it characterises only one location in the system) and that its value can't be measured for one specific year, because CDI is a probability of not fulfilment of FT criterion and for one year gives a value of zero or one. To estimate the probability accurately, data of a long period of time should be available.

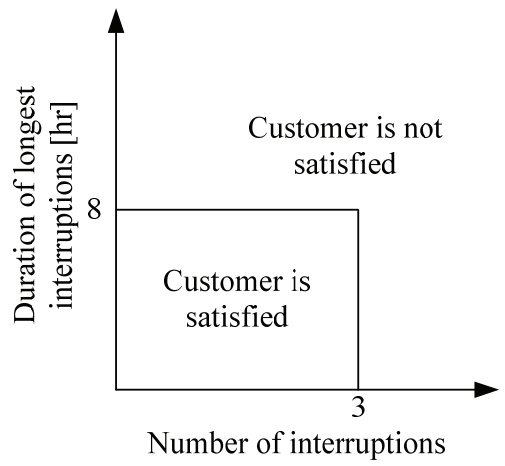

Fig. 1. Relation between satisfaction of customer, number of interruptions and duration of interruptions.

By analogy of SAIDI, SAIFI, CAIDI and other indexes the system average customer dissatisfaction index (SACDI) can be calculated and it is the average value of the CDI over all customers and can be calculated by such equation:

$$
S A C D I=\frac{1}{N} \sum_{i=1}^{N} C D I_{i}
$$

\section{CDI expressions}

For calculation of CDI we should know number $N$ and durations $T_{1}, T_{2}, T_{3}$, etc. of all power supply interruptions of a customer. As it was defined above, CDI is probability that customer will have too many (more than three) or too long (longer than 8 hours) interruptions. So CDI is one minus probability, that customer will not have situation of long or too many interruptions (see equation (2)).

$$
C D I=1-\operatorname{Pr}_{\{s\}}
$$

where $\operatorname{Pr}_{\{\mathrm{s}\}}$ is probability that customer will has no such situation when he will need to complaint. Such situation can be possible in such independent situations:

- No interruption;

- One interruption, shorter than 8 hours;

- Two interruptions and both are shorter than 8 hours;

- Three interruptions and all of them are shorter than 8 hours.

Assuming that all interruptions have the same duration distribution and that they are independent with each other and also do not depend on number of interruptions (assuming that interruptions are exponentially distributed in time), we get the following expression for CDI calculation: 
$C D I=1-e^{-F}-F e^{-F} P_{8}-\frac{1}{2} F^{2} e^{-F} P_{8}^{2}-\frac{1}{6} F^{3} e^{-F} P_{8}^{3}$

where $\mathrm{P}_{8}$ is the probability that duration of interruption lasts less than eight hours, and $\mathrm{F}$ is interruption frequency.

In this expression it is assumed by [2] that duration distribution is Weibull distribution. For Weibull distribution it is assumed that the probability distribution function is

$$
F(t)=1-\exp \left(-\left(\frac{t}{\alpha}\right)^{\beta}\right),
$$

where $\alpha$ is the characteristic value and $\beta$ is the shape factor of the distribution. In case of $\beta=1$ Weibull distribution is exponential distribution. The characteristic value $\alpha$ and the expected value of duration $D$ are related by gamma function of the shape factor:

$$
D=\alpha \Gamma\left(1+\frac{1}{\beta}\right)
$$

Taking into account all mentioned above we can calculate the required probability in such a way:

$$
F_{8}=1-\exp \left(-\left(\frac{8}{D} \Gamma\left(1+\frac{1}{\beta}\right)\right)^{\beta}\right) .
$$

Using equations (3) $\div(6)$ values of CDI can be calculated for different values of interruption frequency and duration times. Results of calculations can be seen from Fig. 2.

\section{SACDI and existing indices}

SACDI and existing system indices like SAIFI, SAIDI and CAIDI are not directly related. Taking into account that the distribution of the time between interruptions and interruption durations for different customers varies widely, SACDI can't be applied to any customer. But with some assumptions mentioned in [2] SACDI can be used for customers connected to one feeder or for similar groups of customers.

Diagram from Fig. 2 can be used to determine requirements for SAIFI and CAIDI taking into account SACDI requirements. For example if we need to get SACDI value of 0.2 we can get it by taking SAIFI $<2.2$ int $/ \mathrm{yr}$ and $\mathrm{CAIDI}<2$ $\mathrm{hr} / \mathrm{yr}$, but also through it could be achieved by $\mathrm{SAIFI}<0.9$ int $/ \mathrm{yr}$ and $\mathrm{CAIDI}<6 \mathrm{hr} / \mathrm{yr}$.

\section{Estimation OF SACDI VALUUE REDUCTION COSTS}

\section{A. The ways of reduction of CDI value}

As soon as CDI value depends on frequency of interruptions and duration of interruptions, it could be improved by diminishing interruption duration under 8 hours and minimizing number of long interruptions.
Power Supply / Elektroapgāde

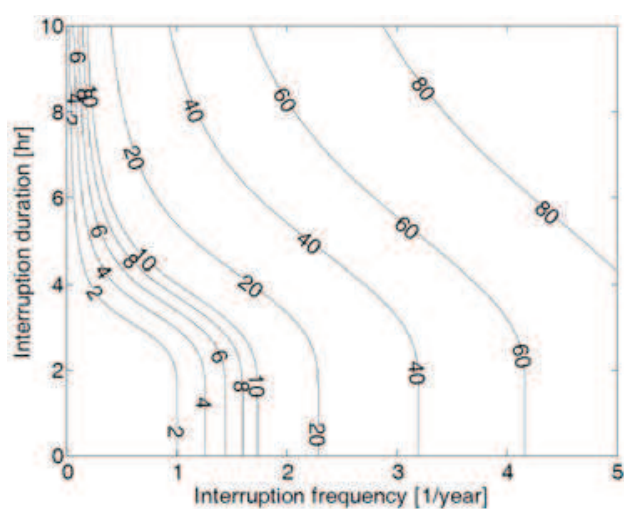

Fig. 2. Diagram for CDI (values in percent). Weibull distribution with shape factor 1.5 .

Interruptions of power supply usually are caused by problems in middle and low voltage networks. This problem is especially serious for countryside networks, where network is formed by overhead lines. The problem of frequent occurrence of power supply interruptions can be solved by partial cabling of the network, especially in places where lines go through forest territories. One more way to improve reliability of power supply is to use distributed generation, i.e. to use standby diesel generators. Due to the fact that improvement of reliability of power supply by partial cabling depends on the environment, where the line is placed, and the length of forest/non-forest territories of the line, accurate calculations of reliability improvement using partial cabling is problematic. Taking into account the fact mentioned above, calculations will be made for the case with diesel generators.

As show calculations performed in [6] usage of diesel generators (DGs) can improve SAIDI, CAIDI and ENS (Energy Not Supplied) indices by more than $20 \%$ (in case if diesel generator of power $500 \mathrm{~kW}$ is placed at the end of the line. Total load of the network is $1692.3 \mathrm{~kW}$ ). Also in [6] it is estimated, that the best performance of DG, from reliability point of view, is when DG is placed at the end of the line.

In [7] calculations of reliability parameters for part of real network (Line21) were performed using software "NEPLAN".

Fig. 3 and Fig. 4, which are placed further, represent original part of network with one DG and upgraded part of network with 3 DGs respectively. Table I and table II show the results of reliability parameters calculations for schemes shown in Fig. 3 and Fig. 4 respectively. According to results of reliability, CDI value was calculated.

Fig. 5 illustrates CDI values for original scheme with one DG, schemes with 3 DGs, 3DGs and cabling of lines N21 and $\mathrm{N} 23$, and for scheme with 5 DGs (two additional DGs are connected to lines N21 and N23. This scheme is not showed in this paper because of shortage of place).

Looking at the diagram of Fig. 5, we can see that in spite of using 3 DGs, CDI value for N21 and N23 is relatively big. So, to solve this problem it was decided to use partial cabling of these parts of network or to add additional generators, which are installed at the ends of these lines. Using partial cabling or installing additional generators leads to diminishing values of CDI for both parts of network below value of 0.2 . 


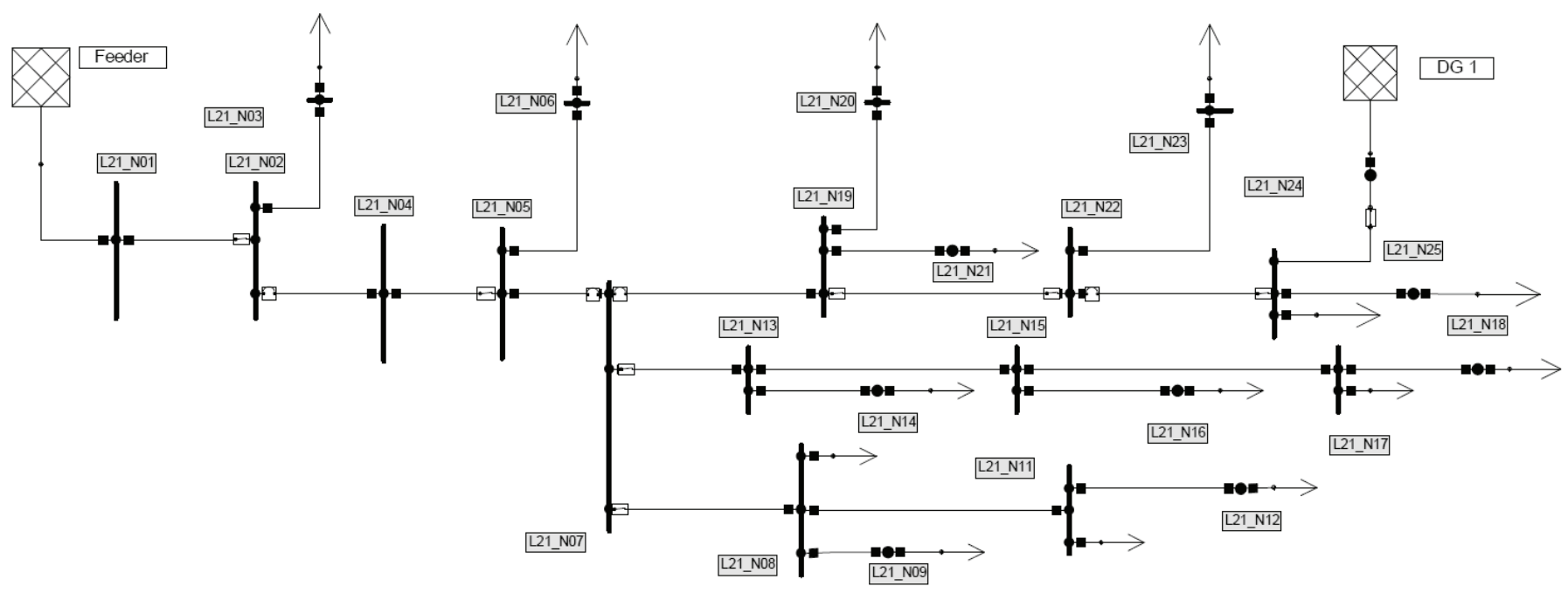

Fig. 3. Part of middle voltage system - line (feeder) L21 with one DG.

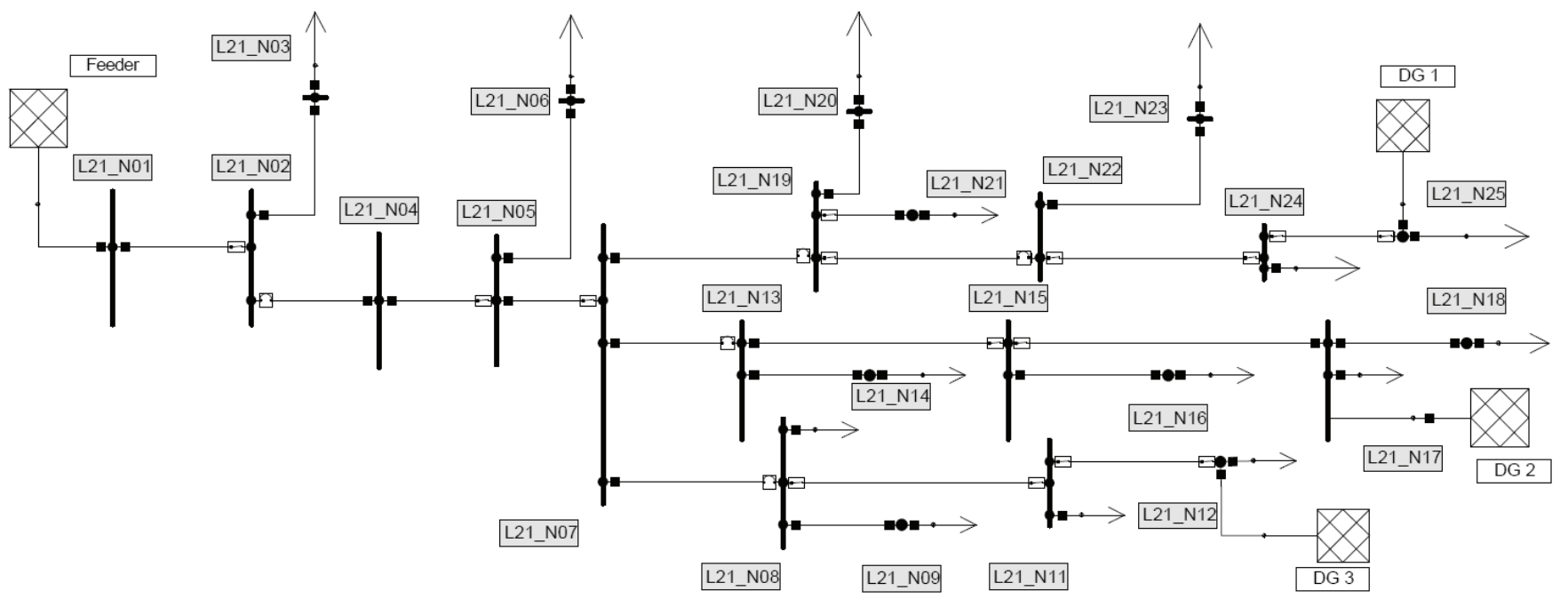

Fig. 4. Part of middle voltage system - line (feeder) L21 with three DGs.

TABLE I

RELIABILITY RESULTS FOR THE LINE21 NETWORK SHOWN IN FIG.3

\begin{tabular}{|c|c|c|c|c|c|}
\hline Element name & F $(1 / y r)$ & T $(\mathrm{h})$ & Fvl $(1 / y r)$ & Fl (1/yr) & CDI \\
\hline L21_L_N03 & 1.317 & 3.29 & 0.043 & 1.274 & 0.080927 \\
\hline L21_L_N06 & 0.946 & 4.477 & 0.155 & 0.791 & 0.151069 \\
\hline L21_L_N09 & 1.921 & 8.276 & 0.126 & 0.795 & 0.678555 \\
\hline L21_L_N10 & 1.921 & 8.276 & 1.126 & 0.795 & 0.678555 \\
\hline L21_L_N11 & 1.921 & 8.276 & 1.126 & 0.795 & 0.678555 \\
\hline L21_L_N12 & 1.921 & 8.276 & 1.126 & 0.795 & 0.678555 \\
\hline L21_L_N14 & 1.921 & 6.724 & 0.795 & 1.126 & 0.56093 \\
\hline L21_L_N16 & 1.921 & 6.724 & 0.795 & 1.126 & 0.56093 \\
\hline L21_L_N17 & 1.921 & 6.724 & 0.795 & 1.126 & 0.56093 \\
\hline L21_L_N18 & 1.921 & 6.724 & 0.795 & 1.126 & 0.56093 \\
\hline L21_L_N20 & 1.858 & 6.299 & 0.681 & 1.177 & 0.509988 \\
\hline L21_L_N21 & 1.858 & 6.299 & 0.681 & 1.177 & 0.509988 \\
\hline L21_L_N23 & 1.858 & 4.816 & 0.375 & 1.483 & 0.356372 \\
\hline L21_L_N24 & 1.836 & 7.433 & 0.904 & 0.932 & 0.601168 \\
\hline L21_L_N25 & 1.836 & 7.433 & 0.904 & 0.932 & 0.6011 \\
\hline
\end{tabular}

TABLE II

RELIABILITY RESULTS FOR THE LINE21 NETWORK SHOWN IN FIG.4

\begin{tabular}{|c|c|c|c|c|c|}
\hline Element name & F $(1 / \mathrm{yr})$ & T $(\mathrm{h})$ & Fvl $(1 / \mathrm{yr})$ & $\mathrm{Fl}(1 / \mathrm{yr})$ & CDI \\
\hline L21_L_N03 & 1.317 & 3.29 & 0.043 & 1.274 & 0.080927 \\
\hline L21_L_N06 & 1.7 & 3.822 & 0.155 & 1.545 & 0.204747 \\
\hline L21_L_N09 & 0.801 & 5.641 & 0.235 & 0.566 & 0.211588 \\
\hline L21_L_N10 & 0.801 & 5.641 & 0.235 & 0.566 & 0.211588 \\
\hline L21_L_N11 & 0.801 & 3 & 0 & 0.801 & 0.009118 \\
\hline L21_L_N12 & 0.801 & 3 & 0 & 0.801 & 0.009118 \\
\hline L21_L_N14 & 0.56 & 4.201 & 0.075 & 0.485 & 0.073712 \\
\hline L21_L_N16 & 0.56 & 6.966 & 0.247 & 0.313 & 0.219103 \\
\hline L21_L_N17 & 0.56 & 6.833 & 0.238 & 0.322 & 0.212071 \\
\hline L21_L_N18 & 0.56 & 6.833 & 0.238 & 0.322 & 0.212071 \\
\hline L21_L_N20 & 1.289 & 3.361 & 0.052 & 1.237 & 0.085861 \\
\hline L21_L_N21 & 1.289 & 6.4 & 0.487 & 0.802 & 0.391159 \\
\hline L21_L_N23 & 2.211 & 4.527 & 0.375 & 1.836 & 0.391447 \\
\hline L21_L_N24 & 2.211 & 3 & 0 & 2.211 & 0.182815 \\
\hline L21_L_N25 & 2.211 & 3 & 0 & 2.211 & 0.182815 \\
\hline
\end{tabular}




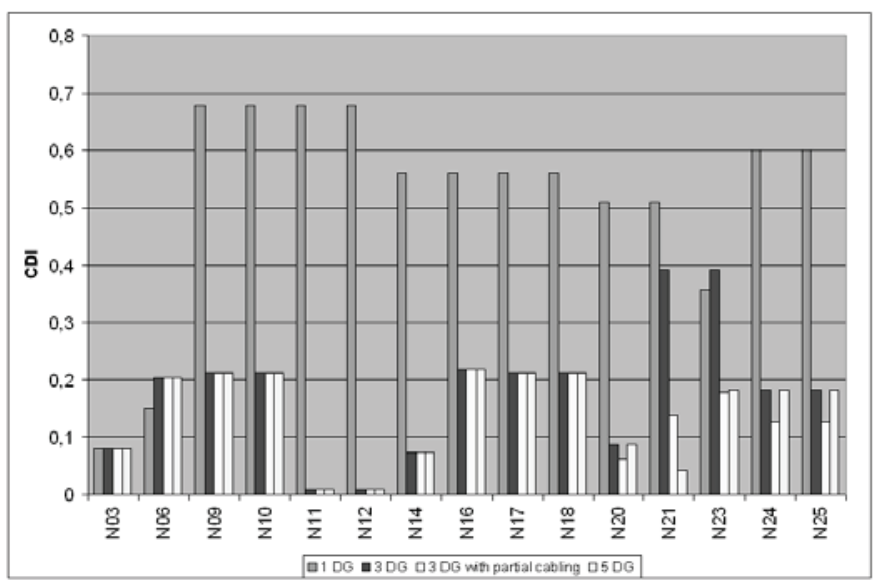

Fig. 5. CDI values for individual lines with different types of reliability improvement enterprises.

\section{B. Costs of SACDI value reduction}

At the paper there are used two ways of reduction CDI (and respectively SACDI) value. In case of usage DGs as way of reduction of CDI value, particular power load of the line or node should be known to choose appropriate power of DG. Prices of DGs vary from $45000 \$$ (approximately $32975 €$ ) per DG with power of $145 \mathrm{~kW}$ to 62000 \$ (approximately 45433 $€)$ per DG with power of $214 \mathrm{~kW}$ and $74899.99 \$$ (approximately $54885 €$ ) per DG with power of $500 \mathrm{~kW}$ [8]. Taking into account all fixed costs related to installing DG (shipping, control house, protection and automation, designing of project, etc.) total initial cost of DG usually doubles [9]. Annual maintenance works are about $733 €$. According to [10] prices of constructing middle voltage cable line in countryside (per $1 \mathrm{~km}$ ) is $28655 \mathrm{Ls}$ (approximately $40773 €$ ).

TABLE III

REDUCTION OF SACDI USING DIFFERENT TYPES OF RELIABILITY IMPROVEMENT

\begin{tabular}{|c|c|c|c|c|}
\hline & $1 \mathrm{DG}$ & $3 \mathrm{DGs}$ & $\begin{array}{c}3 \text { DGs }+ \\
\text { cabling }\end{array}$ & 5 DGs \\
\hline $\begin{array}{c}\text { SACDI } \\
\text { value }\end{array}$ & 0.517908 & 0.178543 & 0.1385088 & 0.141357 \\
\hline $\begin{array}{c}\text { SACDI } \\
\text { reduction }\end{array}$ & $0 \%$ & $65,5 \%$ & $73,3 \%$ & $72,7 \%$ \\
\hline
\end{tabular}

Taking into account that loads of the branches shown in Fig. 4 are not known, we assume that usage of DGs with power of $145 \mathrm{~kW}$ will be appropriate in this situation.

Table III shows SACDI reduction in percent comparing three network modifications with the first network modification (with one DG).

Knowing the new SACDI values for improved networks, we can calculate costs of improving (reducing) the index. Making calculations it is assumed that life cycle of DG is 20 years and life cycle of cable line is 25 years. Table IV gives results of calculations. "Total costs of reduction" shows annual costs of reduction of SACDI in $€$, "Costs of reduction by value 0.1 " shows the costs of reduction of SACDI value by 0.1 , and, finally, "Costs of $1 \%$ reduction" illustrates costs needed for reduction of SACDI value by $1 \%$ (for given network and with assumptions described above).

TABLE IV

COSTS OF REDUCTION OF SACDI ( $€$ YYEAR)

\begin{tabular}{|c|c|c|c|}
\hline & 3 DGs & $\begin{array}{c}\text { 3 DGs }+ \\
\text { cabling }\end{array}$ & 5 DGs \\
\hline $\begin{array}{c}\text { Total costs of } \\
\text { reduction }\end{array}$ & 7145.25 & 12424.25 & 11908.75 \\
\hline $\begin{array}{c}\text { Costs of } \\
\text { reduction by } \\
\text { value 0.1 }\end{array}$ & 2105.5 & 3274.7 & 3162.6 \\
\hline $\begin{array}{c}\text { Costs of 1 \% } \\
\text { reduction }\end{array}$ & 109.1 & 167 & 163.8 \\
\hline
\end{tabular}

\section{V.POSSIBLE WAYS OF APPLICATION OF THE INDEX CDI}

The CDI can be used in network design and planning. To use the index it should be decided what exactly should be limited. On the one hand the value of SACDI can be limited at some pre-defined value, but on the other hand number of customers who's CDI exceeds pre-defined value can be limited. The problem can appear when trying to define the appropriate acceptable level of CDI and SACDI value. Authors of [2] advise to use values of $\mathrm{CDI}=0.25$ and $\mathrm{SACDI}=0.2$ as acceptable values of the indexes. As we can see from Fig. 5 usage of 3 DGs allows reaching CDI value under value of 0.25 for the most part of nodes. Some times it can be economically more efficient not to install additional DGs and pay penalty to unsatisfied customers for power supply interruptions. So, for network planning CDI can be used by applying such equation:

$$
C_{c n s} \cdot \sum_{i=1}^{N_{>p d v}} C D I_{i} \leq N_{D G} \cdot C_{a D G},
$$

where $\mathrm{C}_{\mathrm{cns}}$ are costs or penalty for exceeding CDI value, $\mathrm{N}_{>p d v}$ is number of customers, from all customers $\mathrm{N}$, who's CDI exceeds pre-defined value, $\mathrm{N}_{D G}$ is number of not installed DGs and $\mathrm{C}_{a D G}$ is annual costs of DG unit.

As we can see from results summarized in Fig. 5, both 3 DGs + partial cabling and 5 DGs achieve good results - in both situations CDI and SACDI values are reduced under required values 0.25 and 0.2 respectively. Looking at the results in table IV we can see, that usage of 5 DGs is more preferable comparing with variant with 3 DGs and cabling of $3.24 \mathrm{~km}$ of lines because of the lower costs. In more common situation, when we should give priority to one of the variants partial cabling with reduced number of DGs or usage of more DGs, the next equation can be used:

$$
L_{\text {cable }} \cdot C_{\text {cable }} \leq N_{D G} \cdot C_{a D G},
$$

where $\mathrm{L}_{\text {cable }}$ is total length of cable lines needed and $\mathrm{C}_{\text {cable }}$ is cost of one unit of measurement of cable (e.g. cost of $1 \mathrm{~km}$ of cable line). 


\section{CONCLUSIONS}

In the paper new reliability index has been described. The usage of the index for reliability level increasing was showed. The paper also gives examples of calculations of CDI and SACDI improvement costs. Calculations showed that values of indexes can be improved in different ways, but for accurate calculations very detailed information, like statistics of power supply interruptions for concrete region, loads, prices of DGs and mounting works etc., are required.

The index can be extremely useful for reliability level improvement in cases when speaking about residential customers, because residential customers usually have the lowest interrupted energy assessment rate (IEAR) among the other costumers. According to [11] in Latvia IEAR for residential customers is $1,29 € / \mathrm{kWh}$.

Taking into account present-day legislation of Latvia in power industry, residential customer practically can't get any compensation for power supply interruption. Usage of the CDI and SACDI on one hand, if existing tariffs don't allow to reach pre-defined CDI and SACDI values, gives reason to Transmission System Operator and Distribution System Operator to ask supervision institutions (in Latvia called Public Utilities Commission. Further in text - Commission) for permission to raise tariffs, on the other hand allows Commission to define some penalty for exceeding CDI and SACDI pre-defined values. Penalty can be not involved with real losses of customers (size penalty can be much higher) because the index is not involved with real losses of customers.

Material described in the paper is part of doctoral thesis, and indexes described in the paper will be used as criteria for comparing reliability of power supply during development of methodic for choosing the way of improving reliability of power supply of customers.

This work has been supported by the European Social Fund within the project ,Support for the implementation of doctoral studies at Riga Technical University".

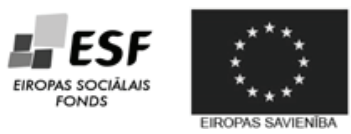

\section{REFERENCES}

[1] IEEE Standard 1366-2003, Guide for electric power distribution reliability indices, May 2004.

[2] M. Bollen, A. Holm, Y. He and P. Owe, A Customer-Oriented Approach Towards Reliability Indices, 19th International Conference on Electricity Distribution (CIRED07), Vienna, Austria, May 21-24, 2007.

[3] Ministry of Economics of Republic of Latvia, Basic viewpoints of development of power industry for time period from the year 2007 to 2016, The 3rd part - basic viewpoints of politics [Online]. Available: http://www.em.gov.lv/em/images/modules/items/item_file_15063_3.doc [Accessed: Mar. 14, 2010].

[4] Hong-Chan Chang, and Teng-Fa Tsao, Reliability cost/worth analysis of distribution systems considering different topologies, 7th International Conference on Probabilistic Methods Applied to Power Systems (PMAPS 2002), Naples, Italy, September 22-26, 2002.

[5] Latvian standard LEK018, Barošanas sprieguma raksturlielumu normas publiskajā elektroapgādes tīklā, January 18, 2002.

[6] I. Waseem, M. Pipattanasomporn, S. Rahman, Reliability Benefits of Distributed Generation as a Backup Source”. Virginia Tech, Advanced research Institute. Arlington. [Online]. Available: http://www.ceage.vt.edu/media/documents/Reliability\%20Benefits\%20o f\%20Distributed\%20Generation\%20as\%20a\%20Backup\%20Source.pdf [Accessed: Mar. 18, 2010].

[7] Y. Yang, M. H. J. Bollen, Considering a Customer Dissatisfaction Index in the reliability of distribution networks with distributed energy resources, 10th International Conference on Probabilistic Methods Applied to Power Systems (PMAPS 2008), Rincón, Puerto Rico, May 25-29, 2008.

[8] Store of diesel generators. [Online]. Available: http://www.peakpowertools.com/default.asp [Accessed: Mar. 14, 2010].

[9] H. L. Willis and W. G. Scott, Distributed power generation, Planning and evaluation. Boca Raton: CRC Press, Taylor \& Francis Group, 2000.

[10] Distribution System Operator in Latvia, Average price of building operations for distribution network in Latvia in year JSC "Sadales tîkls".2008. [Online]. Available: http://www.latvenergo.lv/pls/portal/docs/PAGE/LATVIAN/FILES/aktua litates/Vid_izm_260209.pdf [Accessed: Mar. 29, 2010].

[11] L. Zemīte, J. Gerhards, Evaluation of Distribution Network Customer Outage Costs, The 50th International Scientific Conference Power and Electrical Engineering, October, 2009, Riga, Latvia. Rīga: Izdevniecība "RTU", 2009.

Aleksandrs Lvovs was born in Riga, Latvia, in 1985. He received the B.Sc. and Mg.Sc.ing. degrees from the RTU in 2007 and 2009 respectively. Currently he is $\mathrm{PhD}$ student in RTU. His main research interests include methods for reliability evaluation of electrical networks, systems and equipment and methods for development of power systems planning.

Nowadays he is working at the Latvian TSO-s JSC "Augstsprieguma tîkls" projection division.

He received „Werner von Siemens Excellence Award” in 2009 for his master's work. In 2007 he received paper of distinction form JSC "Latvenergo", LEEA (Latvian association of electrical engineers and electrical system building companies) and LIF (Fund of Latvian education) for victory at the contest of scientifical works in field of power and electrical engineering with his bachelor work.

Contact data: phone: (+371) 25970020, e-mail: aleksandrs.lvovs@inbox.lv

Anna Mutule was born in St.Petersburg, Russia, in 1975. She received the BSc, MSc and Dr.sc.ing. degrees from the Riga Technical University in 1999, 2002 and 2005 respectively. Her main research interests include methods for mathematical modeling of electrical networks and systems; methods for development of power systems planning; dynamic optimization methods and decision systems.

She is leading researcher in the Laboratory of Power System Mathematical Modeling at the Institute of Physical Energetics and also assistant professor of RTU.

She received „Werner von Siemens Excellence Award" for her doctoral work in 2005. She also has paper of distinction form JSC "Latvenergo", LEEA (Latvian association of electrical engineers and electrical system building companies) and LIF (Fund of Latvian education) for leading qualification works of students.

Contact data: phone: (+371) 67558616, fax: (+371) 67550839, e-mail: amutule@edi.lv 